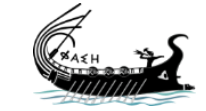

journal.phaselis.org
PHAS KLIS

Issue V (2019)
Disiplinlerarası Akdeniz Araştırmaları Dergisi

Journal of Interdisciplinary Mediterranean Studies

\title{
Phaselis Teritoryumu'nda Kolalemis ve Ailesine Ait Khamosorion ve Çiftlik Yerleşimi
}

\section{Betül GÜREL}

(D) https://orcid.org/0000-0003-0590-9240

\section{Aykan AKÇAY}

(D) https://orcid.org/0000-0002-0035-6862

\section{Nihal TÜNER ÖNEN}

(D) https://orcid.org/ 0000-0002-1098-028X

The entire contents of this journal, Phaselis: Journal of Interdisciplinary Mediterranean Studies, is open to users and it is an 'open access' journal. Users are able to read the full texts, to download, to copy, print and distribute without obtaining the permission of the editor and author(s). However, all references to the articles published in the e-journal Phaselis are to indicate through reference the source of the citation from this journal.

Phaselis: Journal of Interdisciplinary Mediterranean Studies is a peer-reviewed journal and the articles which have had their peer reviewing process completed will be published on the web-site (journal.phaselis.org) in the year of the journal's issue (e.g. Issue IV: JanuaryDecember 2018). At the end of December 2018 the year's issue is completed and Issue V: January-December 2019 will begin.

Responsibility for the articles published in this journal remains with the authors.

c) (i)(2) This work is licensed under a Creative Commons AttributionEY NC SA NonCommercial-ShareAlike 4.0 International License.

Citation B. Gürel - A. Akçay - N. Tüner Önen, "Phaselis Teritoryumu'nda Kolalemis ve Ailesine Ait Khamosorion ve Çiftlik Yerleşimi". Phaselis V (2019) 413-424.

http://dx.doi.org/10.18367/Pha.19028

Received Date: 17.10.2019 | Acceptance Date: 14.12.2019

Online Publication Date: 31.12.2019

Editing Phaselis Research Project

www.phaselis.org 


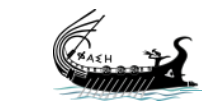

\title{
Phaselis Teritoryumu'nda Kolalemis ve Ailesine Ait Khamosorion ve Çiftlik Yerleşimi
}

\author{
Kolalemis and his Family's Khamosorion and Farm Settlement \\ found in the Territory of Phaselis
}

\author{
Betül GÜREL - Aykan AKÇAY** - Nihal TÜNER ÖNEN***
}

\begin{abstract}
Öz: Bu makale, Phaselis ve teritoryumunda yürütülen yüzey araştırmaları kapsamında, kentin hinterlandında bulunan Üçoluk Yaylası, Uzuntaş Mevkii'nde tespit edilen bir khamosorion ve çiftlik yerleşiminin sayısal görüntüleme metotları ışığında arkeolojik ve epigrafik değerlendirmelerini içerir. Söz konusu khamosorion tipi kayaya oyulmuş mezar ve işlik, yaklaşık 17 metre yüksekliğe sahip bir anakayaya işlenmiştir. Üzerinde mezar ve çiftlik sahibi karı-kocanın portreleri ile bezemelerin işlendiği khamosorion'un günümüze kadar korunmuş olan mezar yazıtı sayesinde, söz konusu kişilerin Kolalemis ile Termela adlarını taşıdığı öğrenilmektedir. Oldukça yıpranmış olan yazıt, sayısal belgeleme metotları ile neredeyse tamamen okunabilmiş ve böylece Phaselis kentinin demografisine yeni kişiler dahil edilebilmiştir. Phaselis Teritoryumu'nda yer alan Uzuntaş ve civarındaki alanda çok sayıda, içinde mezarı da bulunan çiftlik yerleşimi tespit edilmesi, kentin hinterlandında yoğun üretim faaliyetlerinin yürütüldüğünü gösterir.
\end{abstract}

Anahtar sözcükler: Phaselis, Khamosorion, Arkeoloji, Epigrafi, Sayısal Görüntüleme, Fotogrametri, SfM

Abstract: This article includes the epigraphic and archaeological evaluations of a khamosorion and farm settlement found in Üçoluk Yaylası, Uzuntaş location in the light of new imaging methods within the scope of the surveys conducted in Phaselis and its territory. The aforementioned khamosorion and (wine) press were built on a bedrock with a height of approximately 17 meters. It is learned thanks to the inscription of the khamosorion and also the portraits of a couple who are the owners of the grave and the farm settlement that these people were named as Kolalemis and Termela. The applied digital imaging methods to the surface of the khamosorion made it possible to read the highly eroded inscription and thus new people added to the demography of the Ancient City of Phaselis. The various number of sarcophagi and farm settlements in the territory of Phaselis and Uzuntaş location indicate that the intensive farming and production practices were carried out in the hinterland of the ancient city.

Keywords: Phaselis, Khamosorion, Archaeology, Epigraphy, Digital Imaging, Photogrammetry, SfM

* Arş. Gör., Akdeniz Üniversitesi, Akdeniz Uygarlıkları Araştırma Enstitüsü, Akdeniz Eskiçağ Araştırmaları Anabilim Dalı, Antalya. betulgurel@akdeniz.edu.tr, (1) https://orcid.org/0000-0003-0590-9240

** Arş. Gör., Akdeniz Üniversitesi, Akdeniz Uygarlıkları Araştırma Enstitüsü, Akdeniz Eskiçağ Araştırmaları Anabilim Dalı, Antalya. aykanakcay@akdeniz.edu.tr, (0) https://orcid.org/0000-0002-0035-6862

**** Doç. Dr., Akdeniz Üniversitesi, Edebiyat Fakültesi, Eskiçağ Dilleri ve Kültürleri Bölümü, Antalya. nihaltuner@akdeniz.edu.tr, @i] https://orcid.org/0000-0002-1098-028X

Çalışmamıza yayın sürecinde yaptığı katkılardan dolayı Öğr. Gör. Mustafa Şimşek’e teşekkür ederiz. 
Çalışma kapsamında Phaselis ve Teritoryumu Yüzey Araştırmaları'nda ${ }^{1}$ Üçoluk Yaylası, Uzuntaş mevkiinde tespit edilen bir khamosorion ve işlik değerlendirilmektedir. 2017 yılı araştırmalarında tespit edilen alanda, yaklaşık 17 m yüksekliğinde bir anakaya üzerinde, doğu yönde bir khamosorion ve kuzeybatı yönünde bir işlik tespit edilmiştir (Fig. 1). Khamosorion zeminden yaklaşık 4 metre yukarıda başlamaktadır ve mezara ulaşım anakayaya traşlanan merdivenle sağlanmaktadır. Ancak merdivenin sadece son dört basamağı izlenebilmektedir ve zeminle bağlantısı kesilmiştir.

Khamosorion teknesinin ön yüzünde olasılıkla mezar sahiplerine ait tasvirler, floral bezemeler ve tek girland ile çevrilmiş tabula ansata'ya kazınan 13/14 satırık bir yazıt bulunmaktadır. Yazıt oldukça yıpranmış durumdadır ve tam okumasının yapılabilmesi amacıyla, geleneksel metotların yanı sıra (estampaj, el okuması ve fotoğraf) sayısal görüntüleme metotlarıyla da belgelenmiştir. 2018 yılı teritoryum araştırmaları kapsamında alana tekrar gidildiğinde, khamosorion tekne tabanının kaçak kazıcılar tarafından tahrip edildiği görülmüştür. Kırsalda bulunan alanın vandallara karşı korunması, mevcut şartlarla mümkün olmamakla birlikte khamosorion ve işliğin bulunduğu kaya kütlesi, hava fotogrametrisi ve yersel fotogrametri metotları ile belgelenerek sayısallaştırımış ve dijital koruma altına alınmışıı².

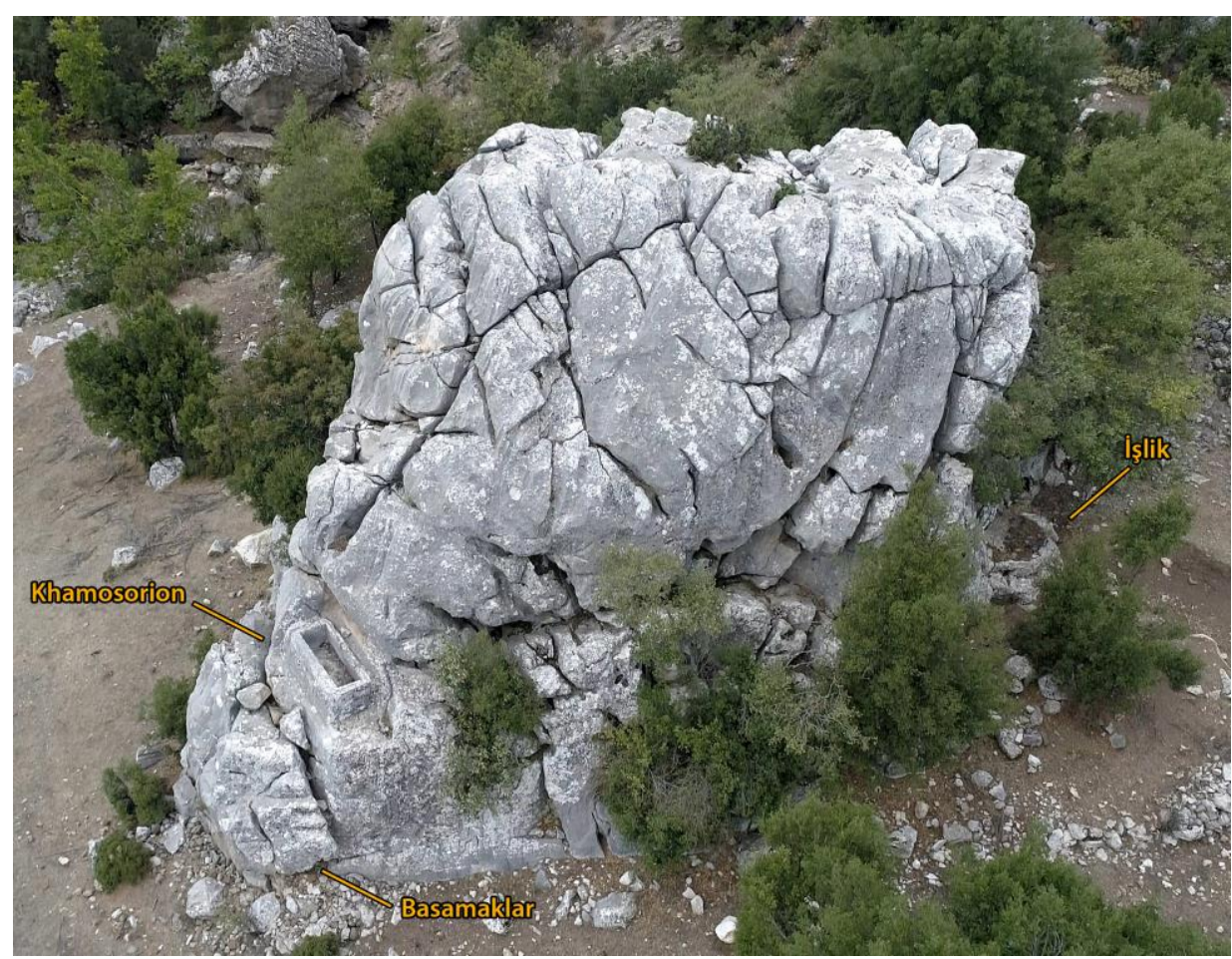

Fig. 1. Anakayaya açılmış khamosorion ve işlik, hava fotoğrafı

\section{Sayısal Belgeleme Çalışmaları}

Çalışma kapsamında anakayanın doğu cephesine merdiveniyle birlikte işlenmiş khamosorion ve aynı kayalığın kuzeybatısında bulunan dörtgen formdaki işlik üzerinde sayısal görüntüleme ve belgeleme çalışmaları yürütülmüştür. Öncelikle insansız hava aracı (iHA) yardımıyla alanda otonom uçuş yapılarak anakaya ve konumlandığı topografyanın jeo-referanslı görüntü verileri kaydedilmiştir. Alanın

1 Phaselis Antik Kenti ve Teritoryumu'nda 2012 yılından itibaren devam eden araştırmalar için bk. Arslan-Tüner Önen 2016, 355-368; 2017, 213-223; 2019, 43-83. Ayrıca bk. Phaselis Araştırmaları resmi web sitesi: www.phaselis.org

2 Kaydedilen tüm sayısal veriler, Phaselis Kazısı veritabanında muhafaza edilmektedir. 
fotogrametrik modelinin elde edilmesi için gerekli olan görüntü verileri alınmıştır³. $2500 \mathrm{~m}^{2 \prime}$ lik alan karelaja bölünerek otonom uçuş planı çıkarılmıştır ${ }^{4} .45$ m irtifada $\% 82$ bindirme oranıyla 86 adet fotoğraf verisi alınmıştır. Bu görüntü verileri üzerinden sayısal topografya oluşturulmuş ve anakayanın üç boyutlu modeli üretilmiştir. Kaydedilen iki boyutlu görüntü verileri (hava fotoğrafları) structure from motion (SFM) algoritmalarıyla işlenerek topografyaya ait sayısal yükseklik modeli ve anakayanın üç boyutlu modeli üretilmiştir (Fig. 2-3).

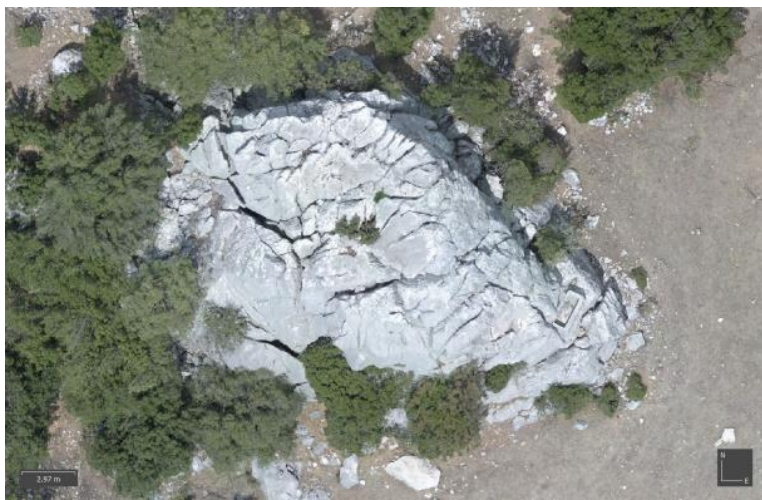

Fig. 2. Ortofoto görünümü

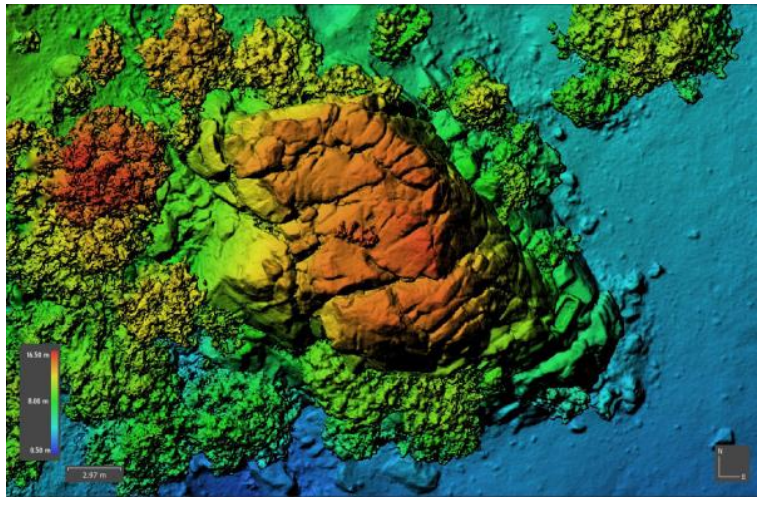

Fig. 3. Sayısal yükseklik modeli (SYM)

Alanın hava fotogrametrisi aracılı̆̆ılla topografik özellikleri ve lokalizasyonu belgelendikten sonra sonra arkeolojik ve epigrafik verilerin analizine yönelik yersel fotogrametri çalışmaları yürütülmüştür. Bu kapsamda khamosorion teknesinin ön yüzünde yer alan figürler, kabartmalar ve yazııın sayısal görüntü verileri kaydedilmiştir. Yüzeyde görülen doğal aşınmalar, liken/mantar tabakasının yanı sıra insan kaynaklı tahribat gibi görsel algıyı zayıflatan unsurları aşabilmek için, analiz aşamasında dijital görüntü verileri kullanılmıştır. Bu kapsamda öncelikle khamosorion teknesinin ön yüzünde yer alan yazıt ve ikonografik unsurlar $\mathrm{H}-\mathrm{RTI} \mathrm{I}^{5}$ metodu ile kaydedilmek istenilmiş ancak mezarın bulunduğu düzlemdeki kayaç zeminde yeterli hareket alanı bulunamadığı için bunun yerine yakın mesafe fotogrametri (close-range photogrammetry) kaydı alınmışır ${ }^{6}$. Kayıt sırasında elde edilen veriler üzerinden arkeolojik ve epigrafik analizlerin yapılabilmesi amacıyla, khamosorion'un yüzeyine ait yoğun nokta bulutu (dense cloud) ve mesh görünümü ile birlikte yüzey normalleri elde edilmiştir. Esere ait foto-gerçek doku yüzeye işlenmesiyle birlikte Uzuntaş khamosorion'una ait üç boyutlu sayısal modelin oluşturulması tamamlanmıştır. Oluşturulan sayısal modeller üzerinden mezarın ikonografik ögelerine ve yazıına dair analiz çalışmaları yürütülmüştür (bk. Fig. 4-8).

3 DJI Phantom 4 Adv. marka/model drone ile 35 mm lens kullanılarak her bir fotoğraf için 20 megapiksellik görüntü kaydı yapılmıştır. Detaylı bilgi için bk. https://dl.djicdn.com/downloads/Phantom_4_Advanced/20171010/Phantom_4_ Advanced_User_Manual-EN.pdf. Kayıt sırasında diğer formatlarda ortaya çıkabilen veri kaybına engel olmak için RAW (ham) formatta kayıt yapılmıştır.

4 Otonom uçuş planının çıkarılması ve uygulanmasında Drone Deploy yazııımının kullanımı tercih edilmiştir. Detaylı bilgi için bk. https://support. dronedeploy.com/docs/3dmodeling-with-drones.

5 H-RTI metodu hakkında bilgi için bk. Mudge et al. 2006, 195-202, Akçay 2016.

6 Üç boyutlu fotogrametrik modellerin oluşturulabilmesi için gerekli olan 'görüntü verisi' alımı aşamasında khamosorion'un ön yüzünü kapsayan 97 adet fotoğraf kaydı alınmıştır. Kaydedilen görüntü verileri Structure from Motion (SFM) algoritmalarıyla işlenmiştir. Structure from Motion, birbiriyle örtüşen iki boyutlu görüntü verilerinin (fotoğraf) bağdaştırılarak nesnelerin 3 boyutlu sayısal modelinin oluşturulmasında kullanılmaktadır. SfM algoritmasını kullanarak nesnelerin sayısal üç boyutlu modellerinin üretildiği farklı fotogrametri yazılımları bulunmaktadır. Çalışmada ele aldığımız khamosorion'un sayısal modelinin oluşturulması aşamasında Agisoft Metashape Pro yazıımının kullanımı tercih edilmiştir. Kayıt sırasında 1/10 mm hassasiyetinde fotogrametrik ölçekler kullanılmıştır. 


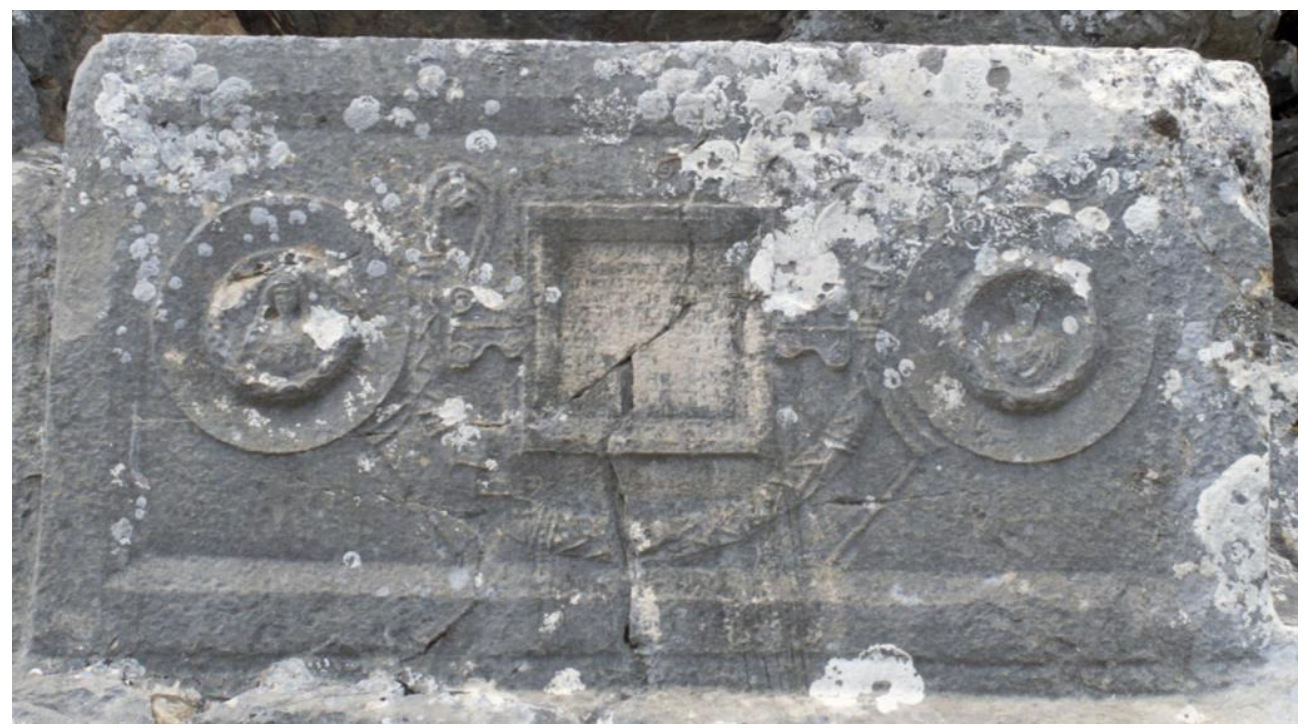

Fig. 4. Khamosorion ön yüz görünümü (fotoğraf).

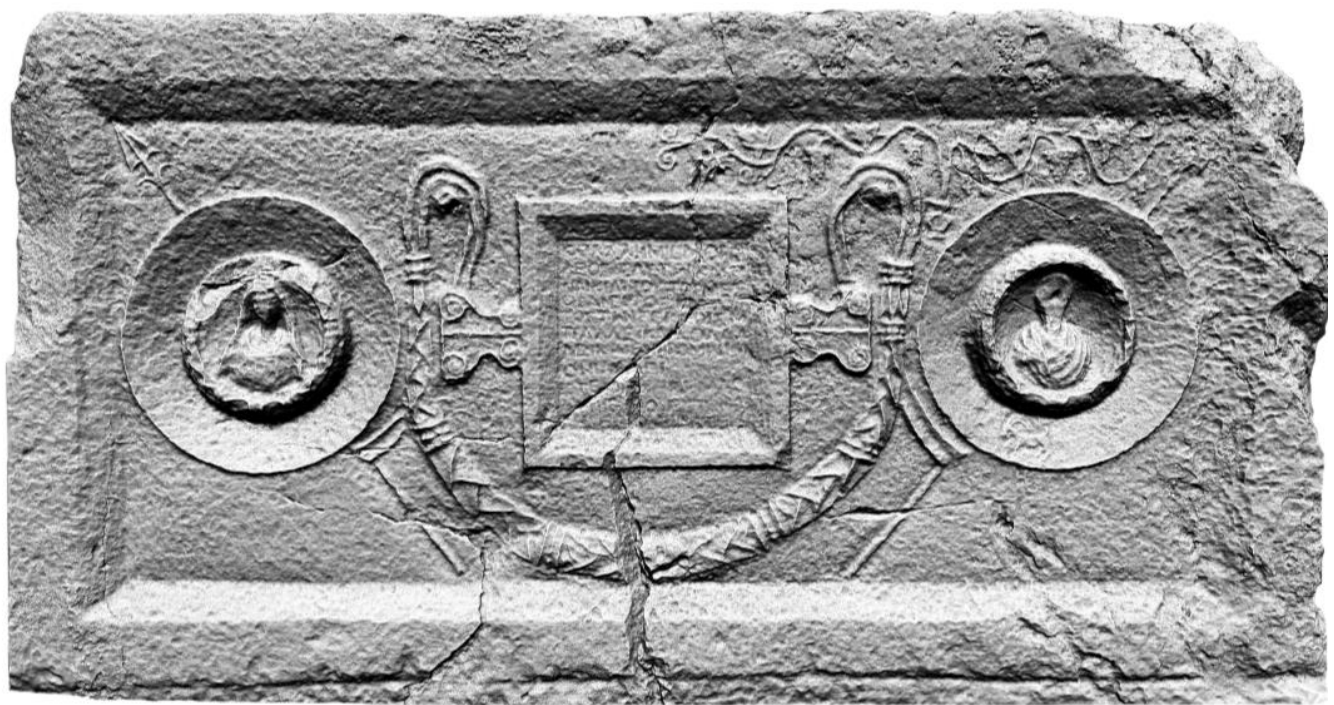

Fig. 5. Khamosorion'un arkeolojik ve epigrafik analizinde kullanılan fotogrametrik 3B model ${ }^{7}$.

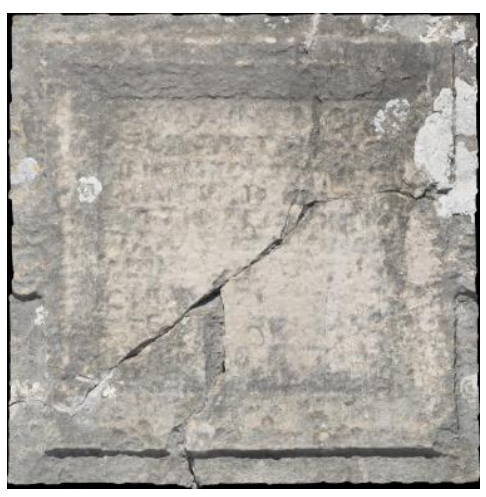

Fig. 6. Yazıta ait orthomosaic görünümü

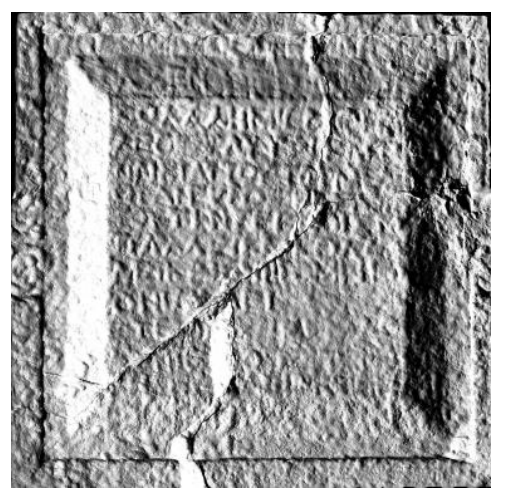

Fig. 7. Yazita ait fotogrametrik modelinin yalın görünümü ${ }^{8}$

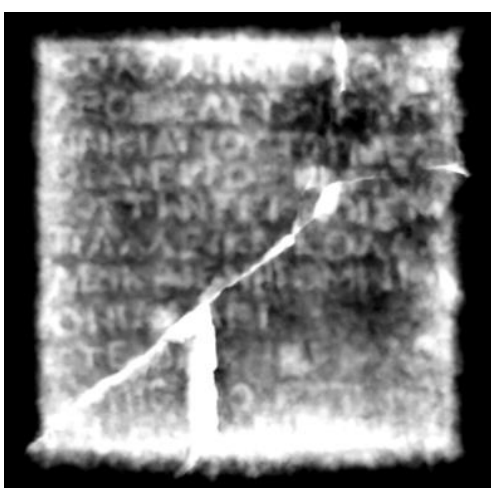

Fig. 8. Yazıt yüzeyine ait fotogrametrik modelin derinlik haritası

Termessos’tan sütunlu bir lahit üzerinde uygulanan benzer fotogrametrik çalışma için bk. Akçay - Gürel 2018, 1-18.

8 Sayısal analiz filterelerinin uygulanmasında MeshLab tercih edilmiştir. Ayrıntılı bilgi için bk. http://www.meshlab.net 


\section{Kolalemis ve Ailesi'ne ait Khamosorion}

Uzuntaş Mevkii'nde tespit edilen khamosorion yaklaşık 17 m yükseklikteki anakaya üzerinde şekillendirilmiştir. Söz konusu mezar, yapısal özellikleri nedeniyle khamosorion olarak adlandırılmıştır zira sadece tabanı kayaca bağı olan ve diğer yüzleri kayaçtan ayrılarak şekillendirilen kaya lahitlerinden farklı olarak bir dar yüz ve arka uzun yüz kayaca bağlı bırakılmıştır ${ }^{9}$. Yerden yaklaşık $4 \mathrm{~m}$ yükseklikteki mezara, anakayaya oyulmuş merdivenlerle ulaşılmaktadır. Mezar yapısı, podyum, tekne ve kapak olmak üzere üç parçadan oluşmaktadır. Podyum ve khamosorion teknesi anakayaya bağlı şekillendirilmiştir. Kayacın 0.20 m yüksekliğinde traşlanmasıyla podyum yükseltisi elde edilmiştir. Khamosorion teknesinin ön uzun yüzü ve bir dar yüzü kayaçtan ayrılacak şekilde traşlanmış, diğer yüzlerde kayaçtan ayrılmamıştır (Fig. 9a-b). Kapak tekne üzerinden kay(dırı))mış kırık iki parça halinde kayacın arasındaki boşluğa sıkışmışır. Mevcut durumda yapılan tespitlere göre kapak formu kırma çatılıdır, köşelerde akroterler mevcuttur ve mahya kirişi vardır. Mezarın oryantasyonu; doğuya bakan ön yüz teraslı tarım arazilerine bakacak şekilde, kuzey-güney doğrultulu tasarlanmıştır. Bu konumlandırma bilinçli olarak tercih edilmiş olmalıdır zira bu şekilde mezar, etrafa hakim bir kayaç üzerinde vadideki yol güzergahını kullanan kişilerin izlenimine açıktır.
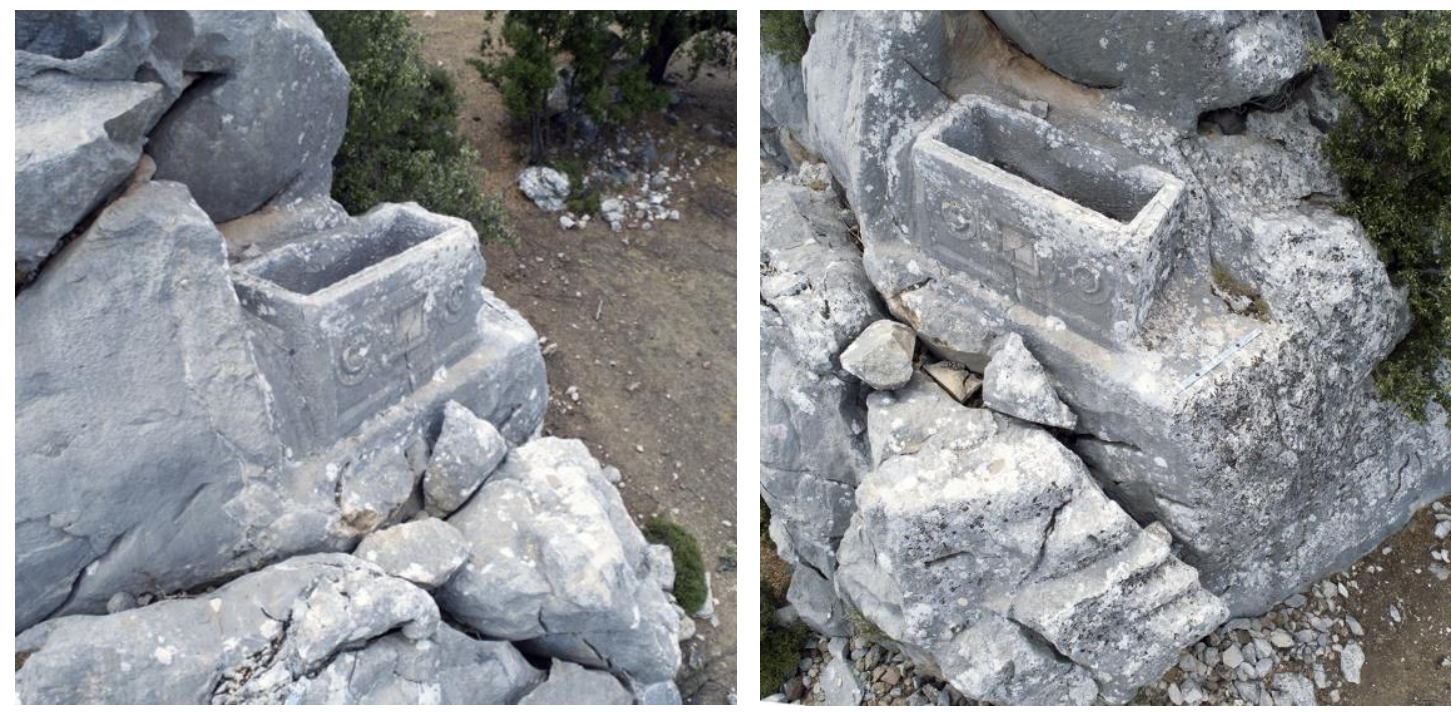

Fig. 9a-b. Khamosorion genel görünüm

Tekne 2.15 m boy, 0.99 m en ve 1.02 m’yükseklik ölçülerindedir. Ön uzun yüz ve bir dar yüzde çeşitli figürler kabartma olarak işlenmişlerdir. Söz konusu figürlerin yer aldığı sahneler -dört kenarı çevreleyecek şekilde- en dışta düz geniş bir silme ve onun içinde iç bükey eğimli daha dar bir silmeden oluşan iki kademeli bir çerçeve ile sınırlandırılmıştır. Ön yüzdeki kabartmalar ve mezar yazıtı, sahnenin merkez noktasından başlayarak yanlara doğru genişleyen bir anlatım içinde ele alınacaktır. Buna göre; sahnenin merkezinde yazıtı taşıyan tabula yer almaktadır. Tabula zeminden yükseltilerek oluşturulmuş iki kademeli dikdörtgen bir çerçeveye sahiptir. Tabulanın sağ ve sol

9 Çelgin, bu tip mezarları "teknelere kısmen kayaların içinde, kısmen dışında meydana getirilmiş khamosorionlar (geçiş tipi lahitler)" olarak sınıflandırmaktadır (Çelgin 1990, 190-200). Burada söz konusu olan khamosorionun ön yüzünde kullanılan bezeme ve figürler, bir lahit cephesi özelliklerini taşımakla birlikte mezarın büyük kısmı kayaca bağlı şekillendirildiği için Çelgin'in sınıflandırmasındaki geçiş tipine uygundur. Termessos'ta khamosorionların kapaklarında iki kısa cephesinde üçgen alınlıklar meydana getiren, semerdam biçiminde kapaklar kullanılmaktadır. Bunların bir kısmında akroter varken bir kısmında ise bulunmamaktadır. 
yanından yatay olarak çıkan "T" şeklindeki dayanakların altında ve üstünde uzanan uçları spiralli motifler ile ansata şekillendirilmiştir. Tabula ansatayı tek halkalı bir girland çevrelemektedir. Girland çizgisel konturlarla belirtilmiş bitki sarmalı taşımaktadır. Girlanda dolanan taenealar, tabula ansatanın iki yanından yükselmekte ve taşıyıcı çivilere asıldıktan sonra iç bükey birer kıvrım yaparak girland altından geçmektedir. Böylelikle çivilere asılan girland taeneaları birer fiyonk yaparak aşağ uzatılmıştır (Fig. 4-5).

Tabula ansatanın iki yanında kalkan ve mızrak birlikteliği tasvir edilmiştir. Kalkanlar iç bükey bombeli hatlara sahip iç içe iki daire şeklindedir. İçteki küçük daire içinde birer insan figürü yer almaktadır. Büyük olasııkla mezar sahibi Kolalemis ile sahibesi Termela'nın betimlendiği söz konusu insan figürleri solda kadın büstü ve sağda erkek büstü yer alacak şekilde kabartma olarak işlenmiştir. Taş yüzeyindeki tahribat nedeniyle figürlerin yüz detayları, uzuvları, ifadeleri gibi detaylar tamamen yok olmuştur. Soldaki kalkan mızrak birlikteği içinde betimlenen Termela'nın yüz çevresi ve boyun çizgisi ile başına attığı örtünün başın iki yanından gövdesine doğru inen kumaşı belirgindir. Solda betimlenen Kolalemis'in baş, boyun ve omuz çizgisi belirgindir ayrıca toga giymekte olduğu ve üst gövdede giysi kumaşının birbiri üstünden atıldığı bölümün kıvrımları izlenebilmektedir.

Erkek büstünün altında, kalkanın dış daire çizgisinin içinde bir dağ keçisi tasvir edilmiştir. Keçi figürü, ayakta ve tabula ansata'ya doğru yönelmiş yürürken verilmiştir. Geriye doğru kıvrılan uzun boynuzları yetişkin bir keçi tasvirini ortaya koymaktadır. Genel vücut hatları, göz çukuru ve geriye doğru kıvrılmış havada duran kısa kuyruğu belirgindir. Keçi tasvirine ait bu detaylar alanda net olarak görülememekle birlikte bu verilere sayısal ortamda ulaşılmıştır. Yine teknenin sağ tarafındaki bir diğer bezeme örgesi ise asma yaprağı ve üzüm salkımı taşıyan dallardır. Erkek figürün resmedildiği kalkan motifi ile girland taeneası arasına yerleştirilen minyatür bir amphora içinden çıkarak sağa ve sola uzanan dallar üzüm salkımı ve asma yaprağı taşımaktadır. Sağa doğru uzanan dal, kalkanın üstünden teknenin köşesine kadar devam etmektedir, bundan sonraki bölüm tahribat nedeniyle görülememektedir. Sola doğru uzanan asma dalı ise tabula ansata'nın ortalarına kadar devam etmekte ve dalın ucu ikiye bölünüp volütlü kıvrımlar yaparak bitirilmektedir. Bu detayların olduğu kısım yoğun liken ve mantar tabakası ile kaplandığı için direkt gözlemle veya fotoğraf aracıIığıyla izlenememiş ancak fotogrametrik analiz sonuçlarıyla ortaya çıkarılmıştır. Teknenin kuzeye bakan dar yüzünde yine kalkan ve mızrak tasviri yer almaktadır. Buradaki kalkanın iç çerçevesi ön yüzlerdeki kalkan tasvirlerinin aksine dışa bombeli olarak verilmiştir ve çizgisel hatlarla altı parçaya bölünerek floral bir görünüm elde edilmiştir.

Phaselis teritoryumu dahilinde yürütülen çalışmalarda, kırsal yerleşimlerde mezar sanatında yer bulan tasvirlerde çoğu zaman alçak kabartma özellikleri taşıyan ve hatta çizgisel hatlara sahip kabartma figürlerle karşılaşılmaktadır. Lahitler üzerindeki düzenleme şemasına bakıldığında kalkan mızrak birlikteliği içinde insan büstleri, tekneyi köşelerde çevreleyen asma dalları, keçi, geyik, köpek ve aslan gibi hayvanların betimlenmesi, bölgenin mezar sanatında yer bulan karakteristik unsurlar olarak nitelendirilebilir ${ }^{10}$.

10 Phaselis teritoryumundaki tespit edilen lahitlerle ilgili olarak bk. Tüner Önen et al. 2017, 343-369; Phaselis kuzeydoğu sınırlarının ulaştığı Antalya Hurma Köyü’nde bulunan lahitlerde de tabula ansata'yı çevreleyen tek girland, kalkan mızrak birlikteliği içinde tasvir edilen insan figürleri, çizgisel hatlara sahip alçak kabartma olarak işlenen hayvan tasvirleri taşıyan lahitler mevcuttur, ayrıntılı bilgi için bk. Çevik 2008, 189 vd. Res. 11-13, 19-20; Phaselis teritoryumundaki Hurma Çiftçi Lahdi için bk. Çelik 2019, 231-249. 
Burada ele alınan khamosorion üzerinde tek hayvan figürü olarak keçi, dikkati çeken farkı bir görünüm ortaya koymaktadır. Genellikle av sahnesi veya hayvan mücadelesi gibi sahneler içinde görmeye alışkın olduğumuz şekilde değil erkek büstü taşıyan kalkanın sınırları içinde olması bu kompozisyonun bilinçli bir tercih olduğunu düşündürmektedir. Söz konusu coğrafya, dağlık bir çiftlik yerleşimi olduğu için özellikle ürün elde edilen hayvanlar günlük yaşam içinde önemli bir yer tutmaktadır. Günümüzde de olduğu gibi bu tür hayvanlardan elde edilen ürünler hem yetiştiricinin ihtiyacını karşılamakta hem de ürün fazlasının satılmasıyla aileye ekonomik katkı sağlamaktadır ${ }^{11}$. Bu yönüyle düşünüldüğünde söz konusu keçi tasviri şaşırtıcı değildir ancak, anakayanın bir nevi podyum olarak kullanılmasıyla büyük bir kaya kütlesinin merkez noktasına oyulmuş, etkileyici bir izlenime sahip bir mezar üzerinde tek hayvan tasviri olması nedeniyle dikkat çekicidir. Gerek mezarın oryantasyonu gerekse üzerinde yer alan diğer bezeme unsurları göz önünde bulundurulduğunda başka hayvan tasvirlerine av veya hayvan mücadelesi gibi sahnelere de yer verilebileceği düşünülmektedir. Bu durum, yerleşimin sosyo-ekonomik yapısında hayvansal üretimin önemli bir katkısı olmasıyla açıklanabilir. Bununla birlikte teknenin sağ tarafında görülen asma dalları, ruhun öteki dünyada var olmaya devam edeceğini -ölümsüzlüğü- temsil etmesinin yanı sıra tarımsal üretim ve bereket ile de ilişkilendirilebilir ${ }^{12}$. Bu çerçeveden bakıldığında, mezar sahipleri kendilerini yücelten sahneler yerine yalın ve gerçekçi tesvirlerle mezarı donatmayı, günlük yaşam düzeni ve ekonomik şartları belirleyen unsurları mezarlarında kullanmayı tercih etmiş görünmektedirler. Fakat buradaki tasvirlerin yerleştirme şemasına bakıldığında dikkat çeken bir unsur daha bulunmaktadır. Teknenin ön yüzüne bakıldığında sağ ve sol tarafı birbirinden ayıran ve kompozisyonda dengeyi bozan bir eşitsizlik söz konusudur. Süsleme örgesi için kullanılan tasvirlerin tümü Kolalemis'in yer aldığı sağ tarafta yığılmıştır. Gerek keçi figürü gerekse minyatür bir seramik kap içinden çıkarak dağılan asma dallarının tasvir edilmesi, ön yüzde bir kompozsiyon şeması ve figür dengesinin gözetilmediğini, bir tarafın daha ağırlıklı olarak gösterişli tasarlandığı hissini vermektedir. Asma dallarının görmeye alışkın olduğumuz şekilde teknenin sağ veya sol alt köşesinden değil, kalkan ile yazıt arasındaki küçük boşluktan filizlenmesi ve ele aldığımız keçi tasviri, Kolalemis'in bulunduğu alanın öne çıkarılmak istendiği duygusunu uyandırmaktadır. Bu kompozisyon teknenin tamamlanmadan bırakıldığı ihtimalini de taşıyor olmakla birlikte erkeğin toplumdaki sosyal statüsü ve üretimin, gelir kaynağının sağlayıcısı baskın taraf olarak görülmesinin mezar sanatına yansıtılması olarak da değerlendirilebilir.

\section{Mezar Yazıtı}

Teknesi tamamen kayaya açılmış olan khamosorion teknesi üzerindeki tabula ansata içerisinde 13 (14?) satırlık yazıt tespit edilmiştir. Oldukça tahrip olmuş olan yazıın ilk iki satırı ve son satırı tabula'nın çerçevesi üzerinde kazınmıştır. İkinci satır dışında sigmalar ve diğer karakterler kufi kazınmıştır.

Ölçüler: yük.: 1.52 m; gen.: 2.25 m; der.: 1.23 m; harf yük.: 0.33-0.26 m.

Tarih: MS III. yüzyıl (harf karakterleri dolayısıyla)

11 Phaselis'in hakimiyet alanında üretilen yöresel ürünler kente ulaşım ve iletişim ağını sağlayan yol sistemleri sayesinde kente ulaştırılmaktadır, ayrıntılı bilgi için bk. Kızgut 2017; Arslan 2018, 15-46.

12 Çelgin 1990, 328. 


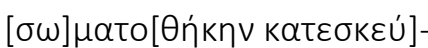

$\alpha \sigma \varepsilon \vee v a c$

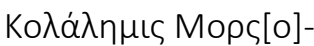

4

$\lambda \varepsilon \varepsilon_{\circ} \dot{\varepsilon} \alpha \cup \tau \tilde{\omega}$ kai үu-

vaıkì aútoũ TEPME^A

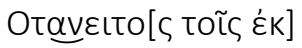

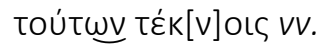

8

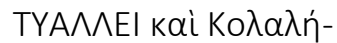

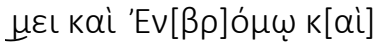

'Oviá $[\lambda] \lambda \varepsilon\llcorner\mathrm{vac}$.

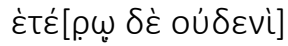

12

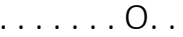

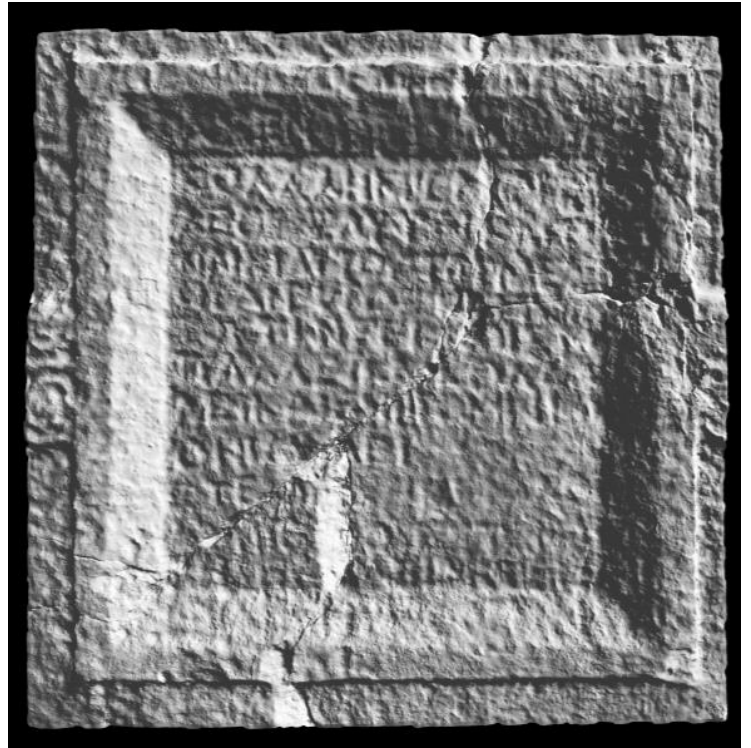

Fig. 10. Mezar yazıtı

Bu lahdi Morsolis oğlu Kolalemis, kendisi ve kendisinin karısı Otanis kızı Termela ile bunlardan olan çocuklar, Tyallis, Kolalemis, Enbromos ve de Oniallis için yaptırdı. Başka hiç kimse için ......

Str. 1-2. Tabula ansata'nın üst çerçevesine kazınmış olan ilk satır oldukça yıpranmış durumdadır. Fakat yine de sayısal görüntüleme sonuçlarından elde edilen veriler doğrultusunda $\sigma \omega \mu \alpha \tau o Ө n ́ k \eta v^{\prime} i n$

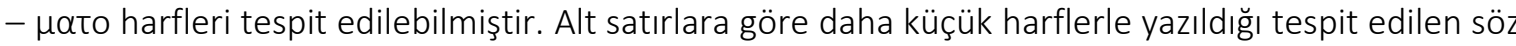
konusu satırda bunun için yer sıkıntısı bulunmamaktadır.

Str. 3-4. Mezarı yaptıran kişi olarak, Morsolis oğlu Kolalemis görünmektedir. Kolalemis yerel bir Anadolu ismidir ve şimdiye kadar sadece Phaselis ve teritoryumunda belgelenmiştir ${ }^{13}$. Bölgede bu ismi taşıyan on sekiz kişi (on üç'ü kent içinde; beş'i teritoryumda) tespit edilmiştir ${ }^{14}$. Bu yazıtla birlikte sayı yirmi'ye çıkmaktadır. Phaselis kentinde önemli görevler üstlenmiş Kolalemis isimli bir vatandaşa ilişkin bir onurlandırma yazıtında bu ailenin söz konusu ismi altı nesildir taşıdığı belgelenmiştir ${ }^{15}$. Yerel bir isim olan Morsolis Pisidia, Isauria ve Paphlagonia bölgelerinden bilinen bir isimse de bu bölgede ilk kez belgelenmektedir ${ }^{16}$.

Str. 5-6. Mezar sahibinin karısına ilişkin bilgiler verilir. Yazıtın bu kısmı aşınmış olsa da RTı yöntemi

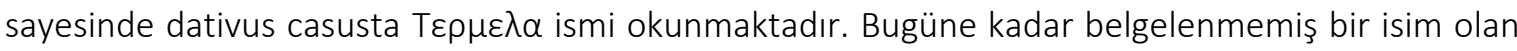
Termela, Uzuntaş'ın yaklaşık 4 km batısında konumlanan Söğüt Cuması yerleşiminden ele geçen bir

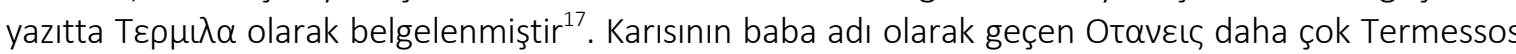
kenti ve teritoryumunda karşılaşılan yerli bir isimdir ${ }^{18}$. Söz konusu isim Ekizce Ares kutsal alanında

13 Krş. Zgusta 1964, $151 \mathrm{vd.}$

14 TAM II/3 1200, 1202, 1204, 1206, 1207, 1210; Adak et al. 2006, 9 vd. nr. 6; SEG VI. 735; SEG LII 1440 ve 1442; Krş. Tüner Önen 2015, 54 vd.

15 Söz konusu Kolalemis ve ailesi hakkında ayrıntılı bilgi için bk. Tüner Önen 2008, 331 vdd.

16 Zgusta 1964, § 968-4.

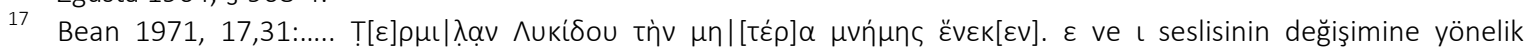
kullanımlar ve örnekler için bk. Gignac 1976, 249 - 256. Pisidia bölgesinde mascilinum şahıs adı olarak belgelenen

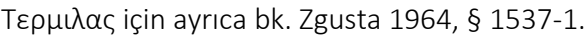

18 Krş. Zgusta 1964, § 1125-1. 
ele geçen bir yazıtta da belgelenmiştir ${ }^{19}$.

Str. 7-10. Mezar sahibi Kolalemis ve karısı Termela'nın çocuklarına ilişkin bilgiler verilir. Yazılanlara göre çiftin dört çocuğu bulunmaktadır. Bunlardan ilki, şimdiye kadar belgelenmemiş olan Tua $\lambda \lambda \iota \varsigma$ adını taşımaktadır. Arykanda, Tyriaion ve Batı Lykia yerleşimlerinden Hippokome'den ele geçen bir yazıtlarda Toa $\lambda \lambda \iota \varsigma^{20}$; Myra ve Perge'de ise Tou $\alpha \lambda \lambda \iota \varsigma^{21}$ ismi belgelenmiştir. Caria kenti Halikarnassos'ta ise $\Theta v a \lambda \lambda \iota \varsigma$ ismi görülmektedir ${ }^{22}$. Diğer çocukların isimleri ise Phaselis teritoryumunda daha

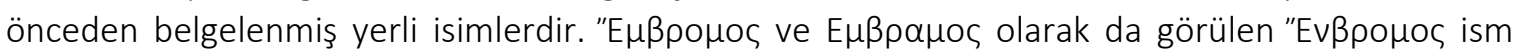
Phaselis ve teritoryumunda on kişiye daha ad olmuştur ${ }^{23}$. "Ovı $\alpha \lambda$ \ıৎ adı da şimdiye kadar sadece Phaselis teritoryumunda belgelenmiş isimlerdendir ${ }^{24}$. Bu isim Ovıa入ıs formuyla da görülmektedir ${ }^{25}$.

Str. 11-13 (14?). Son üç/dört satır oldukça yıpranmıştır. Fakat burada mezara karşı işlenecek suçlara ilişkin ceza ibarelerinin bulunduğu düşünülmektedir. Kent içinden ele geçen İmparatorluk Dönemi'ne tarihli mezar yazıtlarında cezanın ödeneceği kasa daha çok kent kasası ve fiscus olarak belirlenirken, teritoryumdan ele geçen yazıtlarda değişiklik -kent kasası, Athena Polias için tapınak kasası ya da fiscus- göstermektedir. Bu sebeple söz konusu cezanın hangi kasaya ödeneceğ hususunda net bir şey söylemek mümkün gözükmemektedir.

\section{Kaya İşliği}

Uzuntaş Mevkii'ndeki Kolalemis ve ailesine ait khamosorionun yer aldığı anakayanın üzerinde bir adet işlik düzenlemesi de yer almaktadır (Fig. 11-12). İşliğin formu dikdörtgene yakındır, bir köşesi hafifçe yuvarlatılmış olduğu için tam bir dikdörtgen form oluşmamıştır ${ }^{26}$. İşliğin anakayaya bağlı olmayan tekne duvarlarının yüksekliği $0.20-0.30$ m arasında değişmektedir. Anakayaya bağlı olan arka duvarda pres kolunun yerleştirildiği yuva/fulcrum bulunmaktadır. İşliğin taban seviyesinde kayacın dışına açılan akıtma oluğu ile elde edilen sıvının dışarı akıtılması sağlanmıştır. Oluğun önünde sıvının biriktirileceği bir toplama/dinlendirme havuzu düzenlemesi beklenmektedir ancak anakaya duvarlarında bir traşlama görülse dahi form veren bir düzenlemenin varlığından söz etmek güçtür.

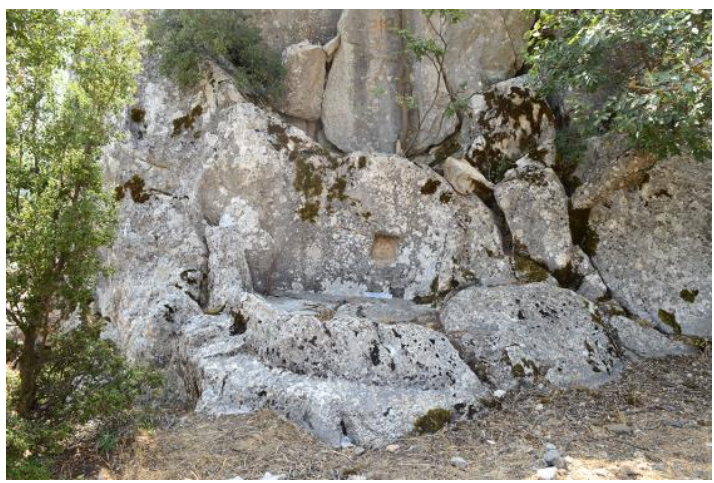

Fig. 11. İşlik genel görünümü

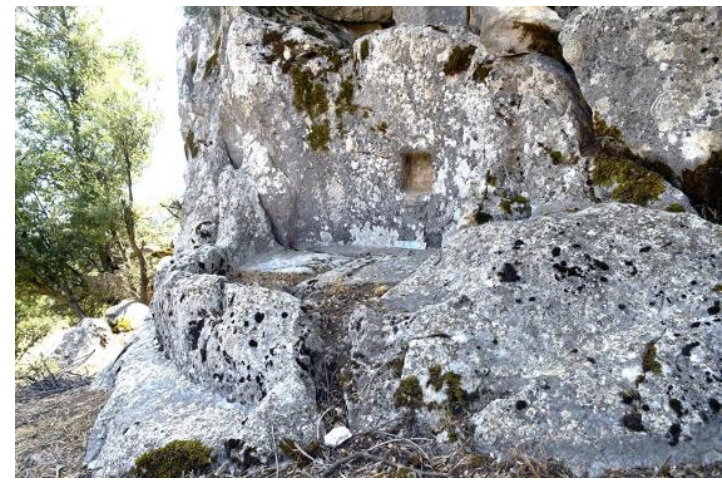

Fig. 12. İşlik akıtma deliği ve pres kolu yuvası

Mevcut izler tahrip olmuş bir toplama havuzuna ya da taşınabilir bir kabın yerleştirildiği düzleme ait olabilir. İşlikteki presleme sürecinin işleyişi hakkında bilgi sağlayan önemli elemanlardan ağırlık taşı/

\footnotetext{
SEG LII 1409.

Şahin 1994, nr.144 ve 162; Naour nr. 51; TAM II 168; Krş. Zgusta 1964, § 1575-4.

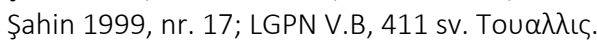

SEG 16, 653 ve 654; SEG 36, 974; Krş. Zgusta 1964, § 438.

Tüner Önen 2015, 50; Tüner Önen et. al. 2017, 357 nr. 3a

Zgusta 1964, § 1091-2; Tüner Önen 2015, 59.

Zgusta 1964, § 1091-1; Tüner Önen 2015, 59.

26 Açık alandaki anakayaya oyulu ezme/pres yatakları bazı örnekleri dikdörtgen olsa da genelde dörtgen ve nadiren yuvarlak forma sahip olarak kategorize edilmektedir, bk. Bulut 2018, 688 vd.
} 
litus etrafta yapılan araştırmalar sırasında işliğin yaklaşık $70 \mathrm{~m}$ batısında bulunmuştur. Taşınabilir bir malzeme olduğu için olasılıkla devşirme olarak kullanılmak üzere in-situ konumundan uzaklaştırılmıştır. Ağılık taşı/litus kırıktır fakat yukarıya doğru daralan konikal formu ile pres koluna bağlantı için açılan yuva üzerindedir. Bu form özellikleri işlikte "baskı kollu pres" sisteminin kullanıldığını ortaya koymaktadır ${ }^{27}$.

Söz konusu alan 1050 m yükseklikte bulunması nedeniyle zeytin yetiştiriciliğine çok uygun değildir. Bu nedenle söz konusu işlik, Uzuntaş mevkiindeki çiflik yerleşimi sakinlerinin şarap üretimi için kullandıkları bir açıkhava tesisi olarak dizayn edilmiş olmalıdır. Zira işlik ve mezarın şekillendirildiği anakayanın doğusunda yükselen eğimli arazide günümüze değin kullanılagelen teraslar mevcuttur. Bu teraslar bölgenin eskiçağ sakinleri tarafından da tarım terasları olarak kullanılmakta ve elde edilen ürün terasların yakınındaki anakayaya oyulu preste işleniyor olmalıydı. Günümüze ulaşan mevcut kalıntılar işlikte ürünü işleme süreci hakkında bilgiler sunmaktadır. İşliği oluşturan tek hücreli tekne bölümü hasat edilen üzümün ayakla çiğnendiği ve duvardaki pres kolu yuvası elde edilen posanın preslenmesi işlemlerinin aynı tekne içinde yapıldığını göstermektedir ${ }^{28}$. Kayalık alanların işlik yapımı için elverişli olması, temizleme kolaylığı ve sağlamlık gibi özelliklerinin yanı sıra açıkhava şarap işliklerinde üzümleri preslemenin fermantasyonu hızlandırması ve su kaybını artırarak şeker oranını yükseltmesi şarap üretimi için tercih edilmesinde önemli bir etkendir ${ }^{29}$.

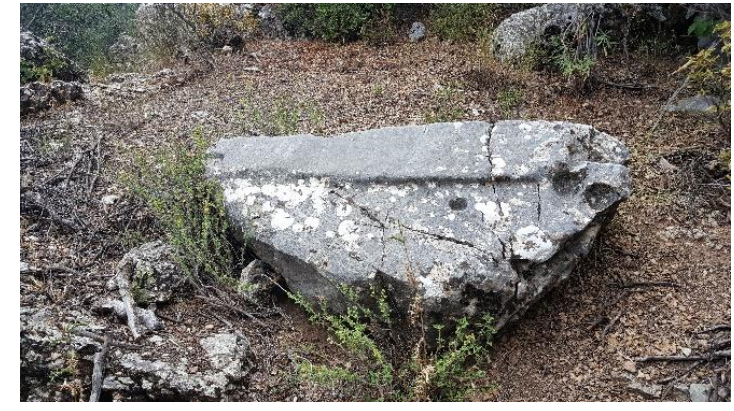

Fig. 13. Lento

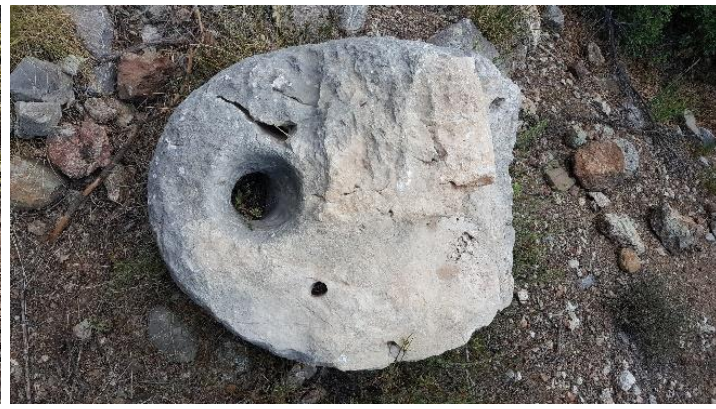

Fig. 14. Ağırlık taşı

Uzuntaş Mevkii'ndeki anakayaya oyulu khamosorion ve işlik, alandaki olası bir çiftlik yerleşiminin varlığını işaret etse dahi yapılan yüzey araştırmaları esnasında bölge içerisinde yerleşik sivil yaşama dair güçlü kanıtlar sunacak arkeolojik bulgulara rastlanmamıştır.

Kayalık alanın batısında uzanan dik yamaçlar üzerinde bir adet kapı eşiği ve yakınında bir adet ağırlık taşı tespit edilmiştir (Fig. 13-14). Sivil yapılaşmalarla bağlantılı olarak bir adet lento dışında başka bir mimari unsurun bulunmaması, alanın hemen güneyinde akan dere vadisinin alanı tahrip etmesiyle ya da anakayanın bitiminden itibaren yükselmeye başlayan eğimli topografyayı bölerek geçirilen modern yolun mevcut yapı kalıntılarını tahrip etmesiyle açıklanabilir. Sonuç olarak, elde edilen veriler yerleşim izlerini net olarak görmeye olanak vermese de, Uzuntaş Mevkii'ndeki günümüze ulaşan kalıntılar civarda yaşayan eskiçağ sakinlerinin, bölgedeki tarım arazilerinde üzüm yetiştiriciliğine ağırlık verdiğini ve elde edilen ürünleri yine burada işleyerek şarap üretimi yaptıklarını işaret etmektedir. Khamosorion'un yer aldığı yüksek noktadan etrafa bakıldığında, tarımsal faaliyetlerin gerçekleştirildiği teraslı araziler görülebilmektedir.

iiler 1994, 510; Bulut 2018, 668; Tlos'tan baskı kollu pres işlik örnekleri için bk . Çilem et al. 2015, 501 vd.

28 Lykia'da kalas yuvaları ile birlikte tespit edilmiş işlikler, ezme ve pres işlemlerinin yapıldı̆̆ı, bölgede yaygın karşılaşılan işlik örnekleri olarak değerlendirimektedir, bk. Bulut 2018, 687 vd.

29 Diler 1995, 446; Bulut 2018, 687; Phaselis Teritoryumu'ndaki terasların sarap üreticiliği, elde edilen ürün miktarı ile ilgili olarak bk. Atilla 2019, 1-30. 


\section{BIBLIYOGRAFYA}

Adak et al. 2006

Alexandrescu 2008

Akçay 2016

Akçay - Gürel 2018

Arslan 2018

Arslan - Tüner Önen 2016

Arslan - Tüner Önen 2017

Arslan - Tüner Önen 2019

Atilla 2019

Bean 1971

Çilem et al. 2015

Bulut 2018

Çelgin 1990

Çelik 2019

Çevik 2008

Diler 1994

Diler 1995

Gignac 1976

Kızgut 2017

LGPN V.A

LGPN V.B
M. Adak, N. Tüner Önen - S. Şahin, "Neue Inschriften aus Phaselis". Gephyra 2 (2006) 1-20.

C. G. Alexandrescu, "Archaeological Finds of "Brass" Instruments in Funerary Contexts". Hrsg. E. Hickmann, A. A. Both, L. Koch - R. Eichmann, Orient Archäologie 22, Studien zur Musikarchäologie VI (2006)163-78.

A. Akçay, "Epigrafi Araştırmalarında Yeni Bir Belgeleme ve Analiz Metodu Olarak RTI". MJH VI/2 (2016) 1-16.

http://dx.doi.org/10.13114/MJH.2016.285

A. Akçay - B. Gürel, "Görülenin Ötesine Gitmek: Sayısal Görüntüleme Metotları Işığında Termessos'tan Sütunlu Bir Lahit Üzerine Yeni Değerlendirmeler". Eds. Murat Arslan - Ferit Baz, Arkeoloji, Tarih ve Epigrafi'nin Arasında: Prof. Dr. Vedat Çelgin'in 68. Doğum Günü Onuruna Makaleler. İstanbul (2018) 1-18.

M. Arslan, "Phaselis ve Teritoryumunun Yol ve Savunma Sistemleri: TekirovaÇamyuva Arası". Phaselis IV (2018) 15-46.

http://dx.doi.org/10.18367/Pha.18002

M. Arslan - N. Tüner Önen, "2015 Yılı Phaselis Antik Kenti ve Teritoryumu Yüzey Araştırması". AST 34/1 (2016) 355-368.

M. Arslan - N. Tüner Önen, "Phaselis ve Teritoryumu Yüzey Araştırması 2016". Anmed 15 (2017) 213-223.

M. Arslan - N. Tüner-Önen, "Phaselis Antik Kenti'nde 2018 Yılında Gerçekleştirilen Yüzey Araştırmaları ve Kazı Çalışmaları “. Phaselis V (2019) 43-83. http://dx.doi.org/10.18367/Pha.19003

D. Atilla, "Phaselis Kenti Ekonomisi'nin 'Ager Publicus' Süreci Kapsamında Değerlendirilmesi". Phaselis V (2019) 1-30.

http://dx.doi.org/10.18367/Pha.19001

G. E. Bean, Journeys in Northern Lycia 1965-1967. Österreichische Akademie der Wissenschaften, Philosophisch-historische Klasse, Denkschriften [DAW], 104. Ergänzungsbände zu den Tituli Asiae Minoris 4. Vienna 1971.

Ç. Uygun - B. Özdemir - K. Sezgin, Arkeoloji, Jeoloji, Doğal ve Kültürel Peyzaj Yapısıyla Tlos Antik Kenti ve Teritoryumu. Ed. T. Korkut. "Zeytin ve Kitap Işlikleri", 496-514. 2015 Antalya.

S. Bulut, "Lykia'da Zeytinyağı ve Şarap Üretimi Üzerine Bir Ön Değerlendirme" Cedrus VI (2018) 675-700.

A. V. Çelgin, Termessos Kenti Nekropol'leri. Yayınlanmamış Doktora Tezi, İstanbul Üniversitesi. İstanbul 1990.

A. Çelik "Hurma Çiftçi Lahdi". Phaselis V (2019) 231-249.

http://dx.doi.org/10.18368/Pha.19015

N. Çevik, "Northeast Lycia. The New Evidence - Results from the past ten years from the Bey Mountains Surface Surveys". Adalya XI (2008) 189-233.

A. Diler, "Akdeniz Bölgesi Antik Çağ Zeytinyağı ve Şarap i̇şlikleri". AST XI (1994) 505-520

A. Diler, "Akdeniz Bölgesi Antik Çağ Zeytin ve Üzüm Presleri-1993". AST XII (1995) 441-457

F. T. Gignac, A Grammar of the Greek Papyri of the Roman and Byzantine Periods: Phonology, Vol. I. Milano 1976.

i. Kızgut, "Antalya Tahtalı Dağ Çevresi Yerleşimlerine İlişkin Yeni Bulgular ve Öneriler". Cedrus V (2017) 199.215.

P. M. Fraser - E. Matthews, A Lexicon of Greek Personal Names, Volume V.A: Coastal Asia Minor: Pontos to lonia. Oxford 2010.

J.-S. Balzat, R. W. V. Catling, É. Chiricat, F. Marchand (eds)., A Lexicon of 
Mudge et al. 2006

Naour 1980

SEG

Şahin 1994

Şahin 1999

TAM

Tüner Önen 2008

Tüner Önen et.al. 2017

Tüner Önen 2015

Zgusta 1964

\section{Betül Gürel - Aykan Akçay - Nihal Tüner Önen}

Greek Personal Names V.B: Coastal Asia Minor:Caria to Cilicia, Oxford 2013. M. Mudge, T. Malzbender, C. Schroer - L. Marlin. "New Reflection Transformation Imaging Methods for Rock Art and Multiple-Viewpoint Display". Eds. M. Ioannides, D. Arnold, F. Niccolucci - K. Mania, The $7^{\text {th }}$ International Symposium on Virtual Reality, Archaeology and Cultural Heritage (VAST'06), Eurographics Association, Nicosia, Cyprus (2006) 195-202.

C. Naour, Tyriaion en Cabalide. Épigraphie et géographie historique. Zutphen 1980.

Supplementum Epigraphicum Graecum.

S. Şahin, Die Inschriften von Arykanda. Inschriften griechischer Städte aus Kleinasien 48. Bonn 1994

S. Şahin, Die Inschriften von Perge I. Inschriften griechischer Städte aus Kleinasien 54. Bonn 1999.

Tituli Asiae Minoris. Wien.

N. Tüner Önen, Phaselis Antik Kenti ve Teritoryumu. Yayımlanmamış Doktora Tezi, Akdeniz Üniversitesi. Antalya 2008.

N. Tüner Önen, B. Gürel, A. Akçay, "Phaselis Teritoryumunda Tespit Edilen Lahitlerin RTI Metodu Işığında Arkeolojik ve Epigrafik Incelemeleri”. Phaselis III (2017) 343-369.

N. Tüner Önen, "Annäherungen zur Geschichte der Stadt Phaselis auf onomastischer Grundlage: Ein Studium der Namen aus Phaselis und ihrem Territorium". Phaselis I (2015) 39-67.

L. Zgusta, Kleinasiatische Personennamen. Prag 1964. 